University of Texas Rio Grande Valley

ScholarWorks @ UTRGV

8-9-2020

\title{
The professional and personal impact of the coronavirus pandemic on US neurointerventional practices: a nationwide survey
}

Kyle M. Fargen

Thabele M. Leslie-Mazwi

Richard P. Klucznik

Stacey Q. Wolfe

Patrick Brown

See next page for additional authors

Follow this and additional works at: https://scholarworks.utrgv.edu/som_pub

Part of the Medicine and Health Sciences Commons

\section{Recommended Citation}

Fargen, K. M., Leslie-Mazwi, T. M., Klucznik, R. P., Wolfe, S. Q., Brown, P., Ansari, S. A., Dabus, G., Spiotta, A. M., Mokin, M., Hassan, A. E., Liebeskind, D., Welch, B. G., Siddiqui, A. H., \& Hirsch, J. A. (2020). The professional and personal impact of the coronavirus pandemic on US neurointerventional practices: A nationwide survey. Journal of Neurolnterventional Surgery, 12(10), 927. https://doi.org/10.1136/ neurintsurg-2020-016513

This Article is brought to you for free and open access by the School of Medicine at ScholarWorks @ UTRGV. It has been accepted for inclusion in School of Medicine Publications and Presentations by an authorized administrator of ScholarWorks@ UTRGV. For more information, please contact justin.white@utrgv.edu, william.flores01@utrgv.edu. 


\section{Authors}

Kyle M. Fargen, Thabele M. Leslie-Mazwi, Richard P. Klucznik, Stacey Q. Wolfe, Patrick Brown, Sameer A. Ansari, Guilherme Dabus, Alejandro M. Spiotta, Maxim Mokin, Ameer E. Hassan, David Liebeskind, Babu G. Welch, Adnan H. Siddiqui, and Joshua A. Hirsch 


\title{
The professional and personal impact of the coronavirus pandemic on US neurointerventional practices: a nationwide survey
}

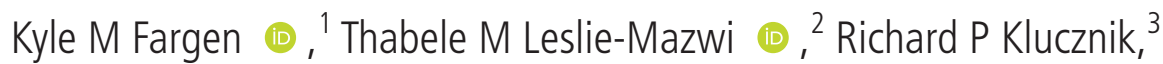 \\ Stacey Q Wolfe, ${ }^{1}$ Patrick Brown 다, ${ }^{1}$ Sameer A Ansari, ${ }^{4}$ Guilherme Dabus 다, ${ }^{5}$ \\ Alejandro M Spiotta, ${ }^{6}$ Maxim Mokin 지, ${ }^{7}$ Ameer E Hassan (1) , ${ }^{8}$ David Liebeskind, ${ }^{9}$ \\ Babu G Welch, ${ }^{10}$ Adnan H Siddiqui, ${ }^{11}$ Joshua A Hirsch (구 ${ }^{12}$
}

For numbered affiliations see end of article.

\section{Correspondence to} Dr Kyle M Fargen, Neurological Surgery and Radiology, Wake Forest University, WinstonSalem, NC 27157, USA; kfargen@wakehealth.edu

Received 15 June 2020 Revised 28 July 2020 Accepted 29 July 2020 Published Online First 9 August 2020
Check for updates

(C) Author(s) (or their employer(s)) 2020. No commercial re-use. See rights and permissions. Published by BMJ.

To cite: Fargen KM, LeslieMazwi TM, Klucznik RP, et al. J Neurolntervent Surg 2020;12:927-931.

\section{ABSTRACT}

Background Little is currently known about the effects of the coronavirus (COVID-19) pandemic on neurointerventional (NI) procedural volumes or its toll on physician wellness.

Methods A 37-question online survey was designed and distributed to physician members of three $\mathrm{NI}$ physician organizations.

Results A total of 151 individual survey responses were obtained. Reduced mechanical thrombectomy procedures compared with pre-pandemic were observed with $32 \%$ reporting a greater than $50 \%$ reduction in thrombectomy volumes. In concert with most (76\%) reporting at least a $25 \%$ reduction in non-mechanical thrombectomy urgent $\mathrm{NI}$ procedures and a nearly unanimous $(96 \%)$ cessation of non-urgent elective cases, $68 \%$ of physicians reported dramatic reductions ( $>50 \%$ ) in overall $\mathrm{NI}$ procedural volume compared with pre-pandemic. Increased door-to-puncture times were reported by $79 \%$. COVID-19-positive infections occurred in 1\% of physician respondents: an additional $8 \%$ quarantined for suspected infection. Sixty-six percent of respondents reported increased career stress, 56\% increased personal life/family stress, and 35\% increased career burnout. Stress was significantly increased in physicians with COVID-positive family members $(P<0.05)$.

Conclusions This is the first study designed to understand the effects of the COVID-19 pandemic on $\mathrm{NI}$ physician practices, case volumes, compensation, personal/family stresses, and work-related burnout. Future studies examining these factors following the resumption of elective cases and relaxing of social distancing measures will be necessary to better understand these phenomena.

\section{INTRODUCTION}

The zoonotic novel $\beta$-coronavirus was identified in the human population in late 2019 and subsequently spread rapidly from Asia across the world. Labeled as the Coronavirus Disease 2019 (COVID19) by the WHO, infection induced by the virus reached pandemic proportions by early March 2020. By mid-March, most US hospitals transitioned into an emergency mode with cessation of all elective, non-urgent procedures and clinic visits, as requested by the US Surgeon General ${ }^{1}$ and supported by recommendations from major physician organizations. ${ }^{2}$ To minimize exposure to physicians and staff, the Society of Neurointerventional Surgery (SNIS) ${ }^{3}$ and others ${ }^{4-6}$ provided recommendations for the continued care of patients requiring emergency neurointerventional procedures.

Across the US, there has been widespread disruption to normal clinical practice. Anecdotally, many centers have noticed reductions in case volumes for emergency procedures during the pandemic. Little is currently known about the effects of COVID-19 on neurointerventional procedural volumes, availability of personal protective equipment (PPE), physician or team member COVID-19 infections or exposures, and the personal or professional toll of the pandemic on physician wellness or burnout. This survey represents a multi-society combined effort, including support from SNIS, the Society of Vascular and Interventional Neurology (SVIN), and the American Association of Neurological Surgeons/Congress of Neurological Surgeons Combined Cerebrovascular Section (CV Section), to better understand these effects.

\section{METHODS}

Institutional review board approval was obtained prior to study initiation. An informal survey writing group committee of six members, with representatives of each of the three specialties that contribute directly to neurovascular care, assembled the survey. The writing group was tasked with composing a concise set of queries to explore the effect of COVID-19 on neurointerventional practices while addressing pertinent practice and demographic factors. The writing group finalized a 37 -question online survey designed with a completion time of approximately $5 \mathrm{~min}$ to optimize response rate (online supplementary materials). This was prepared through SurveyMonkey. Leaders of the SNIS, SVIN, and CV Section were then asked to review and contribute their thoughts to the survey. When the instrument was agreed to, the three societies distributed the survey by email to their respective members soliciting participation completion. In addition, a copy of the email was posted on the SNIS Connect website for SNIS members. Communications contained the link to the survey that 
could be easily accessed with a single click. No compensation was offered to participants. No requests to complete the survey were placed on public social media platforms. All responses were anonymous.

The authors, including acting Presidents from all three of these organizations, estimate a potential sample size of approximately $1,000 \mathrm{NI}$ physicians in the US. SurveyMonkey records the IP address, therefore limiting respondents to a single response. Reminder emails were sent periodically during the study period, which lasted 3 weeks (May 2020).

For many questions, respondents were asked to compare pandemic conditions (mid-March 2020 through date of survey completion) to pre-pandemic conditions (2019 and JanuaryFebruary 2020). Respondents were asked to self-report whether they practice in a COVID-19 epicenter, which was, by design, not clearly defined but instead allowed for individual respondents to report in a subjective manner based on COVID-19 incidence within the surrounding area.

Statistics were performed using IBM SPSS Statistics (v26). Chisquare tests were performed to assess for statistical comparisons, using an alpha-level of 0.05 for determination of significance.

\section{RESULTS}

A total of 151 individual survey responses were obtained for a response rate of approximately $15 \%$ based on the estimated total NI physician sample size. Of these, 135 (89\%) had no missing responses.

\section{Respondent personal and practice characteristics}

Respondent characteristics based on survey questions are shown in table 1 . Most respondents were male and employed at academic hospitals in metropolitan areas. Less than half (44\%) of respondents reported their institution in a COVID-19 epicenter.

\section{Case volumes}

The effect of COVID-19 on NI case volumes is shown in figure 1. Sixty-eight percent of respondents indicated that all elective cases were halted during the preceding months, with $28 \%$ reporting near-complete cessation of elective NI cases except for a few exceptional elective patients. Only 4\% of respondents indicated that most or all elective NI cases continued during the pandemic. The majority of respondents $(68 \%)$ indicated a greater than $25 \%$ reduction in mechanical thrombectomy (MT) for emergent large-vessel occlusion (ELVO) case volumes compared with prepandemic levels (figure 1). In contrast, only $9 \%$ of respondents indicated a higher rate of MT procedures. Similarly, $76 \%$ of respondents indicated more than a $25 \%$ reduction in non-MT urgent NI procedures (ruptured aneurysms, symptomatic carotid stenting, etc.) compared with pre-pandemic. The vast majority (93\%) reported decreased overall NI case volumes compared with pre-pandemic.

\section{Thrombectomy patient care}

Among respondents, only $21 \%$ indicated no change in doorto-puncture times for MT patients. In contrast, 14\% reported an average of $30 \mathrm{~min}$ or longer delay, $35 \%$ indicated an average of 10-30 min delays, and 29\% reported mild average delays in door-to-puncture times of $10 \mathrm{~min}$ or less. During the pandemic, two-thirds of respondents $(67 \%)$ reported no change in their approach to selecting patients for emergent procedures. Just over one-quarter of respondents (27\%) reported being slightly less aggressive in selecting patients for treatment, with $4 \%$ reporting being much less aggressive. In those that reported
Table 1 Personal and practice characteristics of respondents

Number of respondents (\% of total)

\begin{tabular}{|l|l|}
\hline Variable & (\% of total) \\
\hline Training background & $56(37.1)$ \\
\hline Radiology & $41(27.2)$ \\
\hline Neurology & $54(35.8)$ \\
\hline Neurosurgery & \\
\hline Gender & $130(86.1)$ \\
\hline Male & $21(13.9)$ \\
\hline Female & \\
\hline Practice setting & $99(66.0)$ \\
\hline Academic with residents/fellows & $15(10.0)$ \\
\hline Academic without residents/fellows & $36(24.0)$ \\
\hline Private & \\
\hline Years of independent practice & $33(22.2)$ \\
\hline Less than 5 years & $36(24.2)$ \\
\hline $5-9$ years & $53(35.6)$ \\
\hline 10-19 years & $27(18.1)$ \\
\hline More than 20 years & \\
\hline Hospital location & $83(55.3)$ \\
\hline Metropolitan area (population $>1$ million) & $31(20.7)$ \\
\hline Large city (population $500 \mathrm{~K}-1$ million) & $32(21.3)$ \\
\hline Small-medium city (population 50 K-500K) & $4(2.7)$ \\
\hline Rural/community (population <50K) & $77(55.8)$ \\
\hline Hospital located in CoVID-19 epicenter & $61(44.2)$ \\
\hline No & \\
\hline Yes & \\
\hline & \\
\hline
\end{tabular}

reduced aggressiveness in patient selection, the most common reasons for doing so were to protect staff from COVID-19 exposure $(95 \%)$ and to protect themselves and their families from possible exposure (62\%). A minority indicated being less aggressive due to insufficient PPE $(20 \%)$ or as a result of directives from departmental or institutional leadership (20\%).

Only $26 \%$ of physicians reported changing anesthesia practices during the pandemic, with $92 \%$ of those that altered their
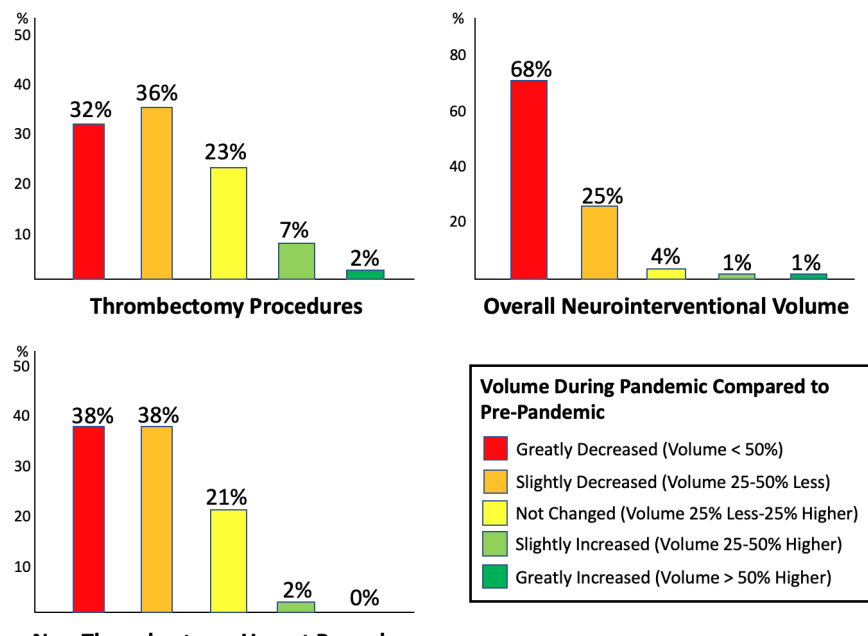

Non-Thrombectomy Urgent Procedures

Figure 1 Reported effects of the pandemic on case volumes compared with pre-pandemic. 
practices converting to general anesthesia from a prior preference of conscious sedation. Of those respondents with unchanged practices due to COVID-19, the distribution of anesthesia preference was split evenly among conscious sedation (50\%) and general anesthesia (50\%).

The majority of respondents indicated that COVID-19 had not had a deleterious effect on the quality of care provided to patients with large-vessel occlusions at their institution (59\%), while marginally, moderately, and severely worsened quality of care was reported by $29 \%, 10 \%$ and $2 \%$, respectively.

\section{Physician and neurointerventional team exposures}

Thirty-eight percent of respondents reported never having examined or performed procedures on a COVID-19-positive patient. Of the remainder, most (41\%) had done so on only one or two positive patients, with $5 \%$ having examined or treated 10 or more COVID-19-positive patients. The vast majority of respondents reported that PPE was either always adequate $(62 \%)$ or adequate most of the time (30\%) for the safety of the NI team.

Of all respondents, only two tested positive for COVID-19 (1\%; neither were hospitalized) and an additional 8\% quarantined but tested negative or quarantined based on symptoms but were not tested. Only 5\% of respondents reported that one or more NI team members (nurses, technologists, physician colleagues) were hospitalized due to COVID-19 infection.

\section{Effects of COVID-19 on workplace, call, and compensation}

Most respondents (87\%) did not have to take additional NI call outside of the norm during the pandemic, with a very small minority having to cover additional call due to a quarantined colleague (9\%) or due to colleagues refusing to participate in call (4\%). Only $9 \%$ of physicians reported being deployed into a role outside of their usual practice during the pandemic due to shortages: in contrast, 58\% reported non-physician members of their NI team being deployed into non-routine roles due to staff shortages.

Nearly half (48\%) reported no changes to their compensation or benefits during the pandemic, while 30\% reported a reduction of $25 \%$ or less and $23 \%$ reported a reduction of greater than $25 \%$ of their normal compensation. Of those that reported reduced compensation, most (56\%) considered this reduction fair and justified.

Only $1 \%$ of respondents reported their employment position being terminated or furloughed, with $3 \%$ reporting that their employment position was likely to be terminated or furloughed in the future.

\section{Personal life and professional burnout}

Most physicians did not have to spend time living apart from their families during the pandemic (82\%) and the overwhelming majority did not have anyone in their immediate family test positive for COVID-19 (95\%). Overall stress related to family life and career and overall career burnout are displayed in figure 2 .

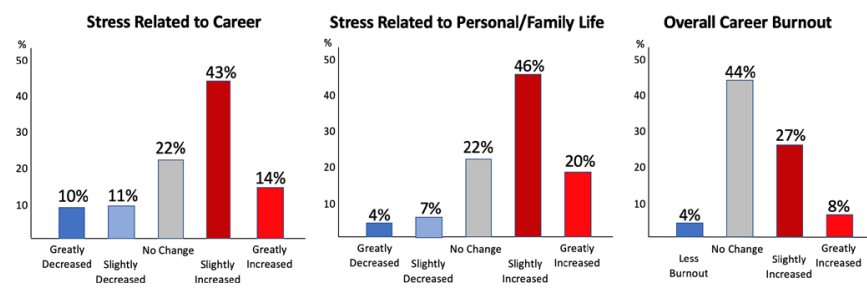

Figure 2 Reported effects of the pandemic on career stress, family and personal stress, and overall career burnout.

\section{COVID-19 epicenters}

Respondents located in epicenters reported significantly higher COVID-19-positive patient exposures compared with nonepicenter respondents $(\mathrm{P}=0.002)$. Forty-nine percent of respondents in non-epicenter locations reported no exposures to COVID-19-positive patients, compared with only $25 \%$ of respondents in epicenters. There was no statistical difference in terms of need to self-quarantine $(\mathrm{P}=0.77)$ or in severely ill NI team members $(\mathrm{P}=0.26)$ based on epicenter status. MT case volume, non-MT urgent procedural volume, and overall procedural volume responses did not differ based on epicenter status $(\mathrm{P}=0.35,0.29$, and 0.29 , respectively). There were no differences in pandemicrelated career burnout $(\mathrm{P}=0.46)$, stress related to work $(\mathrm{P}=0.33)$, or stress related to personal/family life $(\mathrm{P}=0.99)$ between groups.

\section{Other factors}

There was no relationship between hospital location, size, gender, years of practice, or training background on burnout, stress related to career, or stress related to personal/family life (all $\mathrm{P}>0.05$ ). Having children at home with the need for additional schooling/childcare was unrelated to burnout or stress (all $\mathrm{P}>0.05)$. Those respondents with COVID-19-positive immediate family members reported significantly increased personal/ family stress $(\mathrm{P}=0.02)$ and career stress $(\mathrm{P}=0.04)$ compared with those without infected family members.

\section{DISCUSSION}

This is the first study to survey US neurointerventional physicians to understand the effects of the COVID-19 pandemic on physician practices, case volumes, compensation, personal/ family stresses, and work-related burnout. There are a number of important and novel findings from this study.

Most respondents reported reduced MT procedures compared with pre-pandemic, with nearly one-third noting a greater than $50 \%$ reduction in case volumes during the pandemic. In concert with most reporting reduced non-MT urgent NI procedures and a nearly unanimous cessation of non-urgent elective cases, over two-thirds of physicians noted dramatic reductions (>50\%) in NI procedural volume compared with pre-pandemic. These findings add to existing reports that suggest decrements in procedural volumes for specific procedures, such as thrombectomy, ${ }^{7}$ but in contrast provide unique data from operators themselves highlighting the widespread nature of the pandemic's impact.

The neurological manifestations of COVID-19 are becoming more clear, ${ }^{8} 9$ including ELVO in young COVID-positive patients. ${ }^{10}$ There are data suggesting that COVID-19 may induce inflammation, hypoxia, and diffuse intravascular coagulation, and may increase the risk of arterial thrombotic disease. ${ }^{1112}$ Widespread proinflammatory cytokine responses may also contribute to an increased risk of stroke, ${ }^{13}$ which was demonstrated in about 3\% of COVID-positive patients in China. ${ }^{14}$ Paradoxically, many centers have noticed reduced MT procedural incidence, which have until recently been steadily increasing. ${ }^{15} 16$ Recent reports have corroborated the reduced MT volumes in this study. In the state of Michigan, admissions for ischemic stroke and MT procedures were significantly lower during the month of March 2020 compared with immediately prior. ${ }^{17} \mathrm{~A}$ multicenter US study similarly indicated a substantial reduction in MT volumes during the pandemic compared with the year prior with increases in onset-presentation times noted. ${ }^{18}$ This decrease was further supported by a sharp decline in the number of stroke imaging evaluations at the height of the pandemic. ${ }^{19}$ The present survey confirms that a reduction in urgent and 
emergent NI procedural volumes occurred despite most respondents reporting unchanged selection criteria for procedures. The reason for lower procedural volumes remains a matter of investigation. Whether this represents a reduced incidence of stroke or a reduction in stroke presentations for fear of COVID-19 exposure at hospitals and/or consequences of social distancing and isolation is unknown. Future studies examining MT procedural incidence and stroke admissions after the resumption of elective cases and relaxing of social distancing measures will be necessary to better understand this phenomenon.

Importantly, this survey suggests an overall low exposure rate of NI physician and team members. Specifically, NI physician and staff COVID-19 infections were rare, with under 10\% of respondents reporting a need to quarantine or a COVID-19 admission for members of the NI team. Transmission to healthcare workers in the Chinese epicenter was primarily related to lack of appropriate PPE and long-term exposure to positive patients. ${ }^{20}$ Outside of Wuhan, transmission from patients to healthcare workers appears to be relatively low ${ }^{21} 22$ except for those positioned on the front lines in epicenters, ${ }^{23}$ although no robust widespread studies have been published yet. While the majority of respondents in this survey reported having examined or performed procedures on COVID-19-positive patients, very few physicians reported having to self-quarantine or having team members admitted with severe illness. The low number of COVID-19-positive NI physicians is likely due, at least in part, to preserved access to adequate PPE in the overwhelming majority of centers, as indicated by survey responses. Additionally the rapid dissemination of society recommendations, such as that of SNIS, may have played a role in educating and assisting physicians in performing procedures with a safer workflow. Finally, near-universal cessation of elective procedures during the end of March and April likely helped to minimize unnecessary team member exposures. For respondents reporting the need to isolate or that suffered actual infection it is not possible to determine from our data whether the source of exposure is the community or the practice environment.

The personal and professional consequences of the pandemic on NI physician appear less uniform. A plurality of respondents indicated slight increases in work and personal/family-related stress during the pandemic months, yet a plurality reported no overall change in burnout, and paradoxically 0ne-third or more of respondents actually reported reduced work or family stress. Recent surveys of NI physicians and NI non-physician staff members demonstrated self-reported burnout rates ranging between 50\% and 60\%. ${ }^{24}$ In the present survey, about $60 \%-70 \%$ of respondents report either slightly or greatly increased stress involving their career and their personal and family life. However, nearly half of respondents suggest no change or less career burnout compared with pre-pandemic. Studies evaluating risk factors for psychological stress during the pandemic have suggested more pronounced depression, anxiety, and stress in healthcare workers that are single, less experienced, female, and working on the frontline. ${ }^{26}$ In this study, females represented only a small minority of respondents and a low percentage of physicians were allocated to frontline positions outside of their usual scope of practice, which may partly explain discrepancies. An additional factor may be the diminution in caseload, and therefore reductions in direct work-related pressures for physicians, with increased family time now available. Notably, there was no link between burnout and practicing in a pandemic epicenter or not. The only factor significantly related to increased career and personal stress in the present study was having a COVID-19-positive immediate family member, which was rare in the surveyed population (5\%). This finding highlights the opportunity for targeted burnout support measures for practitioners that experience COVID-19 infection in family members in the future. Although many respondents do report increased career stress and almost half suffered reduced compensation, only a small percentage reported concerns regarding employment sustainability.

The global COVID-19 pandemic is unprecedented within our lifetimes. There is no time in recent history where non-urgent patient procedures or visits have been suspended. Consequently, there are no validated instruments that have been developed for understanding or analyzing the impact of the pandemic on healthcare delivery. This survey represents a novel attempt to study the general effects of the pandemic specifically on the NI landscape, surveying members of the three major societies (SNIS, SVIN, and the AANS/CNS CV Section) for a unique scope. As expected, this study confirms widespread disruption of NI practices with dramatic reductions in case volumes and substantial perceived effects on MT processes and quality of care. Surveys designed to address highpriority issues in other medical specialties have unanimously demonstrated marked disruptions in clinical practice. ${ }^{27-30}$ Although the present study did not specifically address the effects of COVID-19 on neurovascular research, a concomitant study has also revealed widespread disruptions in aneurysm and stroke clinical trials due to missed enrollments and protocol deviations from missed clinical or imaging follow-up ${ }^{31}$ These broad vantage points are particularly important given the widespread fears about resurgent infection, ${ }^{32} 33$ with the persistence of the virus in communities across the US. This data helps inform current responses, but also future ones in the event of subsequent pandemics.

There are several important limitations to this approach. As a survey study, this study is subject to the inherent limitations of survey methodology, including recall and selection bias. Many of the survey responses were subjective in nature, for example severity of effect on quality of care which may be interpreted differently among practitioners and is particularly subject to recall bias. However, many responses were allowed to remain subjective in nature to encourage broader physician engagement and completion of the survey instrument. A number of potentially important demographic or practice specific questions, such as region, were not included in the survey by the writing group to ensure anonymity of respondents. The questions used were not previously validated and were designed specifically for the NI physician population, which may limit their generalizability to other specialties and may make comparison with data from other surveys less valid. The relatively low rate of physician response (approximately 15\%) may be seen as a limitation. The reasons for this relatively low response rate are unclear, but one possibility is the potential impact of pre-existing administrative and clinical burdens of maintaining NI services during the COVID-19 pandemic. Response rates could arguably be improved by performing the survey in the post-pandemic setting, however, conducting the study in a delayed fashion also would likely introduce a more considerable effect of recall bias.

\section{CONCLUSIONS}

This is the first study to survey US neurointerventional physicians to understand the effects of the COVID-19 pandemic on physician practices, case volumes, compensation, personal/ family stresses, and work-related burnout. Reduced MT procedural volumes were widely reported with over two-thirds of physicians reporting dramatic reductions $(>50 \%)$ in NI procedural volume compared with pre-pandemic. NI physician and staff COVID-19 infections were quite rare, with under 10\% of respondents reporting a need to quarantine or a COVID-19 admission for members of their NI teams. A plurality of physicians reported increased occupational and personal stress. 
Future studies examining these factors following the resumption of elective cases and relaxing of social distancing measures will be necessary to better understand these phenomena.

\author{
Author affiliations \\ ${ }^{1}$ Neurological Surgery and Radiology, Wake Forest University, Winston-Salem, North \\ Carolina, USA \\ ${ }^{2}$ Neurosurgery, Massachusetts General Hospital, Boston, Massachusetts, USA \\ ${ }^{3}$ Neuroradiology, Houston Methodist Hospital, Houston, Texas, USA \\ ${ }^{4}$ Radiology, Northwestern University Feinberg School of Medicine, Chicago, Illinois, \\ USA \\ ${ }^{5}$ Interventional Neuroradiology and Neuroendovascular Surgery, Miami Neuroscience \\ Institute and Miami Cardiac \& Vascular Institute - Baptist Hospital, Miami, Florida \\ USA \\ ${ }^{6}$ Neurosurgery, Medical University of South Carolina, Charleston, South Carolina, \\ USA \\ ${ }^{7}$ Neurosurgery, University of South Florida, Tampa, Florida, USA \\ ${ }^{8}$ Department of Neurology, University of Texas Rio Grande Valley, Treasure Hills, \\ Harlingen, Texas, USA \\ ${ }^{9}$ Neurology, UCLA, Los Angeles, California, USA \\ ${ }^{10}$ Neurosurgery, University of Texas Southwestern Medical Center, Dallas, Texas, USA \\ ${ }^{11}$ Neurosurgery, University at Buffalo, Buffalo, New York, USA \\ ${ }^{12}$ NeuroEndovascular Program, Massachusetts General Hospital, Boston, \\ Massachusetts, USA
}

Correction notice This article has been corrected since it was published Online First. Affiliation 8 was corrected to 'Department of Neurology, University of Texas Rio Grande Valley, Treasure Hills, Harlingen, Texas, USA'

Twitter Joshua A Hirsch @JoshuaAHirsch

Contributors Concept design: KF, JH. Survey design: KF, JH, MM, AS, GD, TL, PB. Survey distribution: all authors. Manuscript composition: KF, JH, TL, PB, MM, AS, RK. Final approval for article: all authors.

Funding The authors have not declared a specific grant for this research from any funding agency in the public, commercial,or not-for-profit sectors.

Competing interests None declared.

Patient consent for publication Not required.

Ethics approval IRB approval obtained at Wake Forest, \#IRB00065891.

Provenance and peer review Not commissioned; externally peer reviewed.

Data availability statement All data relevant to the study are included in the article or uploaded as supplementary information. All data relevant to the study are included in the article.

This article is made freely available for use in accordance with BMJ's website terms and conditions for the duration of the covid-19 pandemic or until otherwise determined by BMJ. You may use, download and print the article for any lawful, non-commercial purpose (including text and data mining) provided that all copyright notices and trade marks are retained.

\section{ORCID iDs}

Kyle M Fargen http://orcid.org/0000-0001-8979-1993

Thabele M Leslie-Mazwi http://orcid.org/0000-0002-4191-2466

Patrick Brown http://orcid.org/0000-0001-9100-2084

Guilherme Dabus http://orcid.org/0000-0003-1582-6035

Maxim Mokin http://orcid.org/0000-0003-4270-8667

Ameer E Hassan http://orcid.org/0000-0002-7148-7616

Joshua A Hirsch http://orcid.org/0000-0002-9594-8798

\section{REFERENCES}

1 Luthi S. Surgeon General advises hospitals to cancel elective surgeries. Politico, 2020. Available: https://www.politico.com/news/2020/03/14/surgeon-general-electivesurgeries-coronavirus-129405 [Accessed 5 May 2020].

2 ,American College of Surgeons. COVID-19: recommendations for management of elective surgical procedures; 2020. https://www.facs.org/covid-19/clinical-guidance/ elective-surgery

3 Fraser JF, Arthur AS, Chen M, et al. Society of Neurolnterventional Surgery recommendations for the care of emergent neurointerventional patients in the setting of COVID-19. J Neurointerv Surg 2020;12:539-41.

4 Leslie-Mazwi TM, Fargen KM, Levitt M, et al. Preserving access: a review of stroke thrombectomy during the COVID-19 pandemic. AJNR Am J Neuroradiol 2020:41:1136-41.
5 Fiorella D, Fargen KM, Leslie-Mazwi TM, et al. Neurointervention for emergent large vessel occlusion during the COVID-19 pandemic. J Neurointerv Surg 2020;12:537-9.

6 Aggour M, White P, Kulcsar Z, et al. European Society of Minimally Invasive Neurological Therapy (ESMINT) recommendations for optimal interventional neurovascular management in the COVID-19 era. J Neurointerv Surg 2020;12:542-4.

7 Kansagra AP, Goyal MS, Hamilton S, et al. Collateral effect of Covid-19 on stroke evaluation in the United States. N Engl J Med Overseas Ed 2020;383:400-1.

8 Bridwell R, Long B, Gottlieb M. Neurologic complications of COVID-19. Am J Emerg Med 2020:38:1549.e3-1549.e7.

9 Sweid A, Hammoud B, Bekelis K, et al. Cerebral ischemic and hemorrhagic complications of coronavirus disease 2019. Int I Stroke 2020;1747493020937189.

10 Oxley TJ, Mocco J, Majidi S, et al. Large-Vessel stroke as a presenting feature of Covid-19 in the young. N Engl J Med 2020;382:e60.

11 Klok FA, Kruip MJHA, van der Meer NJM, et al. Confirmation of the high cumulative incidence of thrombotic complications in critically ill ICU patients with COVID-19: an updated analysis. Thromb Res 2020;191:148-50

12 Klok FA, Kruip MJHA, van der Meer NJM, et al. Incidence of thrombotic complications in critically ill ICU patients with COVID-19. Thromb Res 2020;191:145-7.

13 Mehta P, McAuley DF, Brown M, et al. COVID-19: consider cytokine storm syndromes and immunosuppression. Lancet 2020;395:1033-4.

14 Mao L, Jin $H$, Wang M, et al. Neurologic manifestations of hospitalized patients with coronavirus disease 2019 in Wuhan, China. JAMA Neurol 2020;77:683-9.

15 Williams MM, Leslie-Mazwi T, Hirsch JA, et al. Real-world effects of late window neurothrombectomy: procedure rates increase without night-time bias. J Neurointerv Surg 2020:12:460-4

16 Williams MM, Wilson TA, Leslie-Mazwi T, et al. The burden of neurothrombectomy call: a multicenter prospective study. J Neurointerv Surg 2018:10:1143-8.

17 Pandey AS, Daou BJ, Tsai JP, et al. Letter: COVID-19 pandemic - the bystander effect on stroke care in Michigan. Neurosurgery 2020. doi:10.1093/neuros/nyaa252. [Epub ahead of print: 04 Jun 2020].

18 Schirmer CM, Ringer AJ, Arthur AS, et al. Delayed presentation of acute ischemic strokes during the COVID-19 crisis. J Neurointerv Surg 2020;12:639-42.

19 Kansagra AP, Goyal MS, Hamilton S, et al. Collateral effect of Covid-19 on stroke evaluation in the United States. N Engl J Med 2020;383:400-1.

20 Wang J, Zhou M, Liu F. Reasons for healthcare workers becoming infected with novel coronavirus disease 2019 (COVID-19) in China. J Hosp Infect 2020:105:100-1.

21 Heinzerling A, Stuckey MJ, Scheuer T, et al. Transmission of COVID-19 to health care personnel during exposures to a hospitalized patient - Solano County, California, February 2020. MMWR Morb Mortal Wkly Rep 2020;69:472-6.

22 Canova V, Lederer Schläpfer H, Piso RJ, et al. Transmission risk of SARS-CoV-2 to healthcare workers - observational results of a primary care hospital contact tracing. Swiss Med Wkly 2020;150:w20257.

23 Breazzano MP, Shen J, Abdelhakim AH, et al. New York City COVID-19 resident physician exposure during exponential phase of pandemic. J Clin Invest 2020. doi:10.1172/JCI139587. [Epub ahead of print: 28 May 2020].

24 Fargen KM, Ansari SA, Spiotta A, et al. Influence of thrombectomy volume on nonphysician staff burnout and attrition in neurointerventional teams. J Neurointerv Surg 2020. doi:10.1136/neurintsurg-2020-015825. [Epub ahead of print: 03 Apr 2020].

25 Fargen KM, Arthur AS, Leslie-Mazwi T, et al. A survey of burnout and professional satisfaction among United States neurointerventionalists. J Neurointerv Surg 2019:11:1100-4.

26 Elbay RY, Kurtulmuş A, Arpacıoğlu S, et al. Depression, anxiety, stress levels of physicians and associated factors in Covid-19 pandemics. Psychiatry Res 2020;290:113130

27 Martinelli F, Garbi A. Change in practice in gynecologic oncology during the COVID-19 pandemic: a social media survey. Int I Gynecol Cancer 2020. doi:10.1136/ijgc-2020001585. [Epub ahead of print: 07 Jun 2020].

28 Sharma A, Maxwell CR, Farmer J, et al. Initial experiences of US neurologists in practice during the COVID-19 pandemic via survey. Neurology 2020;95:215-20.

29 Morray BH, Gordon BM, Crystal MA, et al. Resource allocation and decision making for pediatric and congenital cardiac catheterization during the novel coronavirus SARS-CoV-2 (COVID-19) pandemic: a US multi-institutional perspective. J Invasive Cardiol 2020;32:E103-9.

30 Patel RJ, Kejner A, McMullen C. Early institutional head and neck oncologic and microvascular surgery practice patterns across the United States during the SARSCoV-2 (COVID19) pandemic. Head Neck 2020;42:1168-72.

31 Rai AT, Leslie-Mazwi TM, Fargen KM, et al. Neuroendovascular clinical trials disruptions due to COVID-19. potential future challenges and opportunities. $J$ Neurointerv Surg 2020. doi:10.1136/neurintsurg-2020-016502. [Epub ahead of print: 30 Jun 2020].

32 Xu S, LiY. Beware of the second wave of COVID-19. Lancet 2020:395:1321-2.

33 West CP, Montori VM, Sampathkumar P. COVID-19 testing: the threat of falsenegative results. Mayo Clin Proc 2020;95:1127-9. 